\title{
A CRÍTICA AO ENSINO DA MATEMÁTICA
}

\author{
THE CRITIC IN THE MATHEMATICS TEACHING
}

\section{Marisa Rosâni Abreu da Silveira ${ }^{1}$}

\section{RESUMO}

O discurso que fala da matemática está disperso nas vozes e nos lugares de significação a que aluno e professor têm acesso, interferindo no ensino e na aprendizagem da disciplina. Esse discurso constitui-se como memória discursiva, perpetuandose através das enunciações pelos sujeitos. É nestas enunciações que se encontra a possibilidade de resignificar a matemática.

Palavras-chave: Ensino e aprendizagem da Matemática, Dificuldades de aprendizagem, Discurso.

\section{ABSTRACT}

The speech related to Mathematics is dispersed through voices and in the senses that students and teachers may have access, interfering in the Mathematics teaching/learning. This speech constituted a discourse memory, perpetuating itself through the subjects' statements, there we can find the possibility of resignifying It

Key words: Mathematics Teaching/Learning, Learning difficulty, Speech.

A crítica que se faz ao ensino da matemática resulta da constatação do fracasso do aluno na disciplina. As constantes reprovações servem como um indicativo que faz soar o alarme de que algo está mal na escola. Neste contexto, a responsabilidade de tal fracasso recai no seu ensino, logo quem fracassa não é o aluno, e, sim, o professor. Afinal, de quem é a responsabilidade? Do aluno que estuda e não aprende ou do professor que "dá aula" e não ensina?

Recentemente, uma colega, aluna do Doutorado em Matemática "Pura", em tom de lamento, contou-me que seu professor disse a ela e às suas colegas, todas professoras universitárias: "Se vocês não entendem nem isto, então vão vender Avon".

A conversa com a colega me fez pensar que o seu desagrado com os ensinamentos recebidos provavelmente deve ser similar àqueles que oferece aos seus alunos. Este professor talvez tenha "recomendando" que suas alunas vendessem "Avon", porque tal atitude não exige muitos conhecimentos matemáticos, mas também porque é uma atividade reservada às mulheres, o que recai no mito de que "matemática é para poucos".

Trago este depoimento para ilustrar alguns dos problemas no ensino e na aprendizagem da matemática, tanto no ensino fundamental e médio, como na pós-graduação. Será que a pergunta pela responsabilidade do fracasso não deveria ser reformulada? Não seria mais conveniente perguntar pelos problemas que a matemática apresenta, quando se pretende aprendê-la e ensiná-la?

Ao supormos que a matemática tem algumas características singulares, que a diferenciam das demais disciplinas, e se o professor reconhece tais características, é provável que os problemas em seu ensino sejam amenizados.

O professor muitas vezes não percebe que não tem o "controle" do processo educacional, pois não tem "controle" do processo interno do seu aluno. As teorias educacionais colocadas em prática não garantem o sucesso prometido. Esta promessa não cumprida se manifesta em sentimento de frustração no professor, num crescente descrédito de seu papel na escola e também num desencantamento com o processo educacional, ao perceber que seu aluno não aprende.

Stella Baruk (1996) é severa não apenas em suas críticas às propostas construtivistas aplicadas à disciplina matemática como também ao tratamento psicológico recomendado aos estudantes. Ao comentar sobre o enquadramento do perfil dos 
estudantes propostos pelos manuais de psicanálise/psicologia, alerta:

Procurar os buracos, procurar as faltas, querer reparar os disfuncionamentos, a impossibilidade é pura e simplesmente pressupor que eles podem explicar uma inaptidão da criança. Substituir o postulado, antigo, do aluno "não dotado" pelo postulado moderno, da criança que tem perturbações do "lógico-matemático" é substituir o cancro pelo doente (p. 52).

Seguindo em suas análises, a autora cita a tentativa sem sucesso de uma investigação para tentar encontrar tipos de bloqueio intelectual em matemáticas nas crianças do ensino elementar. A pesquisa relatada num dos manuais verificou que não se tratava de um bloqueio intelectual, e, sim, de um bloqueio puramente afetivo, geralmente devido à ansiedade da mãe.

A autora refuta tal argumento, pois crianças "bloqueadas" por pais "bloqueados" estariam fadadas ao insucesso em matemática até o momento que seus pais resolvessem desbloquear-se.

As análises da autora nos levam a refletir sobre a ilusão de um sucesso garantido pelas diferentes teorias educacionais. Apesar de estas análises terem sido feitas em escolas francesas, a realidade educacional brasileira parece não ser muito diferente, pois como os nossos educadores têm necessidade de segurança e êxito em seus empreendimentos em sala de aula, também acabam aderindo às teorias educacionais como um modismo.

Atualmente, o professor que não se diz construtivista é rotulado como "professor tradicional" e visto com maus olhos perante a comunidade escolar. Este até pode conduzir o aluno a construir o conceito almejado com o uso de ações imaginadas, mas se não fizer uso de material concreto em sala de aula será considerado um professor desatualizado.

Os professores estão constantemente experimentando novas técnicas que possibilitem o desenvolvimento das habilidades dos alunos na aquisição de conhecimentos matemáticos. Além do construtivismo, existe a possibilidade de um trabalho com modelagem matemática, que, segundo Bean (2001, p. 49), "tem um enfoque no qual os alunos criam modelos matemáticos para representar situações dadas. Ou seja, é semelhante aos procedimentos para as resoluções de problemas". É possível também trabalhar com uma abordagem etnomatemática, que é uma forma de perceber o meio cultural em que vive o aluno, buscando atividades em sala de aula que explorem o conhecimento desta cultura. Porém, apesar destas diferentes formas de tentar ensinar ${ }^{2}$, muitas perguntas ainda continuam sem respostas.

Por que as pessoas que fazem cálculos matemáticos com muita eficiência não conseguem colocar no papel os seus "malabarismos" mentais? Qual a dificuldade em representar aquilo que se conseguiu no plano da abstração?

De acordo com Wittgenstein (1987), a intuição não caminha com o material morto da escrita. Quando o sujeito escreve, supõe-se que o texto escrito esteja endereçado a um leitor. Em sala de aula, o professor escreve para o aluno, mas a sua escrita com símbolos universais da matemática não garante a sua significação na leitura do aluno (individual).

Além da dificuldade de nomear o que está no plano da intuição, o signo matemático é "morto" na perspectiva do aluno. Na sala de aula, o professor, como leitor modelo, auxilia o aluno a dar vida a este signo "morto". Porém, a significação do signo isolado, às vezes, não adquire sentido na operação.

Esse fato explica o motivo de alguns alunos, inclusive adultos do ensino superior, não saberem somar frações corretamente. Os alunos se prendem apenas à representação simbólica dos algarismos e não contemplam o sentido da operação.

Por exemplo, é comum alguns alunos somarem $1+1 / 2$ e encontrarem como resultado $2 / 2$. Partindo do pressuposto que eles saibam que $1 / 2$ representa a metade de algo, como pode ser possível que algo inteiro somado com a sua metade seja $2 / 2$ que é o próprio inteiro?

Para Kant, um juízo falso resulta quando o sujeito toma o modo subjetivo (o sentido dado ao objeto) da representação como objetivo. Ao se contentar com o que vê, ou seja, ao atribuir sentido apenas na intuição, através do qual o objeto nos é dado (o fenômeno), o sujeito pode tomar a aparência como verdade. Ao ressaltar que "a aparência não deve atribuir-se aos sentidos, mas ao entendimento", Kant diz:

Quando o fenômeno nos é dado, somos ainda inteiramente livres para, a partir dele, julgar a coisa como quisermos. $\mathrm{O}$ fenômeno funda-se nos sentidos, mas o juízo depende do entendimento e a única questão é saber se, na determinação do objeto, existe ou não verdade. Mas, a diferença entre verdade e o sonho não resulta da natureza

${ }^{2}$ As principais fontes de discussão e busca de soluções para os problemas do ensino de matemática se encontram nas publicações da Revista do Professor de Matemática, sob a direção da Sociedade Brasileira de Matemática, e nas publicações A Educação Matemática em Revista, sob a direção da Sociedade Brasileira de 
das representações, que se referem aos objetos, pois elas são idênticas em ambos, mas da sua conexão segundo regras que determinam a ligação das representações no conceito do objeto (1987, p. 60).

Como "o conhecimento requer dois elementos: primeiro, o conceito pelo qual em geral um objeto é pensado (a categoria), e, em segundo, a intuição pela qual é dado" (p. 86), temos que um objeto matemático pensado não garante que seja conhecido.

Ora, se indagássemos ao sujeito que cometeu o erro acima relatado: como pode um inteiro mais a sua metade ser igual a um inteiro? Seria provável que admitisse estar errado. No momento em que é refeita a pergunta, esse sujeito pode reconhecer o seu erro nesta mudança de contexto, pois não está mais diante de uma linguagem cifrada, e sim conduzido a refletir sobre a soma feita. É no diálogo entre professor e aluno que muitas vezes acontece o entendimento.

Para Wittgenstein (1996, p. 42), "pode-se dizer: com a denominação de uma coisa não se fez nada ainda. Ela também não tem nome, exceto no jogo". Desta forma, temos que significar com o jogo, pois existe relação entre o que pensamos e o que falamos, daí decorre que pensamento é linguagem. Significação só existe nos contextos (relação com o outro). É pelo uso (emprego) que se determina o significado das palavras.

Porém, se admitirmos que o sujeito que errou a soma, mesmo refletindo sobre sua resposta, continuasse com a resposta errada, poderíamos dizer que o seu erro é lógico, pois continuar a admitir que um inteiro mais uma metade resulta em um inteiro é ilógico. Como pensamento é linguagem, pode-se dizer que este pensamento é lógico na perspectiva do aluno, já que não existe pensamento ilógico.

Assim, é conveniente perguntar como atribuímos sentidos aos enunciados. No referido exemplo, a adição dos numeradores, feita mecanicamente, parece não apresentar sentido para quem conclui que $1+1 / 2=2 / 2$.

Perguntar pelas condições da possibilidade deste sujeito, conhecer o significado da proposição, é supor que se tenha acesso à linguagem na qual está escrita tal proposição. Supor neste um sujeito consciente, que fala consigo mesmo e que reflete sobre algo coloca o professor numa posição diferente, na qual percebe que o sujeito aprende no jogo da sala de aula, no diálogo com o seu professor e com a disciplina.
O que devo calcular? Como posso calcular (resolver)? Como posso saber se está certo o que estou calculando? São perguntas que não encontram respostas quando o sujeito lê o texto em linguagem matemática e não compreende, pois não consegue traduzir suas palavras. Esta situação pressupõe que esteja centrado em seu problema e falando consigo mesmo.

A pergunta mais adequada parece ser: Como o aluno produz significados em matemática no contexto da sala de aula? Quais jogos de linguagem são mais eficientes para o aluno produzir significados?

A construção possível de outra linguagem na matemática é um dos problemas que os alunos encontram para responder um questionamento. "Não entendi o enunciado" é um argumento comum na voz dos alunos. Assim, não basta o aluno ter construído todos os conceitos que envolvem um dado problema, é necessário a conexão destes conceitos. No exemplo da soma referida anteriormente, o aluno sabe que $1 / 2$ representa a metade de algo, ou seja, o conceito de metade está construído, porém dar-se conta que um inteiro pode ser representado por $2 / 2$, e que $1 / 2+2 / 2=3 / 2$ deve ser uma obviedade para um aluno de terceiro grau, mas não é.

Para Wittgenstein (2000, p. 31), “um significado de uma palavra é um gênero de utilização desta. Porque é aquilo que aprendemos quando a palavra é incorporada na nossa linguagem". De acordo com o que se infere do autor, a palavra "metade" para o suposto aluno tem significado, já que é provável que seja utilizada no seu cotidiano.

O conceito de metade, portanto, tem significado para o aluno, pois é incorporado em sua linguagem e "é por isso que existe correspondência entre os conceitos, 'regra' e 'significado"'. Porém, "quando os jogos de linguagem mudam, há uma modificação nos conceitos, e, com as mudanças nos conceitos, os significados das palavras mudam também"(p. 31).

No cotidiano, a palavra "metade" tem um significado, no momento de fazer a conta, tem outro, e, ao responder aos questionamentos do professor, quando este o faz refletir sobre o cálculo efetuado, temos mais um significado possível. Mudam os jogos de linguagens, mudam os conceitos.

No cotidiano, obter a metade de uma maçã é facilmente resolvido com uma faca que corta a fruta ao meio; a metade cortada mais uma maçã inteira resulta em uma maçã e meia. Na sala de aula, $1 / 2+1$ 
representa uma linguagem cifrada que o aluno tem que traduzir, ou seja, representa uma das duas partes em que foi dividido o inteiro mais outro inteiro.

Atualmente, por inferência de teorias como a construtivista, exige-se do professor de matemática que mostre ao aluno como os conteúdos matemáticos conseguem relacionar-se com o cotidiano. Porém, nem sempre isso é possível. Assim, o professor tem que fazer um grande esforço para conseguir tal peripécia, e o aluno deve esforçarse para acreditar que tudo que está ao seu redor é matematizável.

Stella Baruk (1996) critica a demanda de que a matemática deva expressar problemas do cotidiano. Através da pedagogia crítica e social dos conteúdos, José Roberto Boettger Giardinetto (1998) também discute, no texto Matemática escolar e matemática da vida cotidiana, a problemática da supervalorização do conhecimento cotidiano frente à situação atual do ensino de matemática, manifestando, assim, uma secundarização da importância da apropriação do saber escolar.

Não podemos acreditar cegamente numa teoria educacional, já que a nossa compreensão sobre uma teoria não pode ter rumo definido. Devemos ficar atentos ao aderirmos a uma prática, pois esta pode abrir outras possibilidades de intervenção na aprendizagem do aluno.

Com a impossibilidade de descrever o processo mental do aluno, é conveniente levantarmos alguns dados que, temporariamente, podem fornecer algumas explicações para o problema de incompreensão na matemática.

Stella Baruk (1996, p. 326), ao comentar o extrato de um texto que tem como especificidade a prática pedagógica e os problemas de pessoas que sofrem de afasia, que "é a perda da palavra, ou a impossibilidade de compreendê-la", questiona os objetos onde a palavra necessária seria insuficiente:

São os objetos mortos, as coisas mortas do material pedagógico. Se não são os objetos, são as palavras que devem morrer. E com elas, as coisas. E é exatamente o que acontece, porque, cada vez mais, a Pedagogia ativa mata a realidade das palavras e das coisas por querer a todo custo, e sem nunca o explicar, misturá-lo com a Realidade.

A crítica da autora refere-se não apenas às tentativas que a psicologia faz ao discutir os insucessos dos estudantes na escola, mas também à ênfase pedagógica da experiência do aprendiz com o objeto.

Os objetos pedagógicos são "mortos" porque, muitas vezes, eles não têm significado para o aluno. Amontoados de materiais sobre a mesa do aluno mais confundem o objeto de estudo do que esclarecem. O material concreto que tem como função a experiência do aluno com o objeto não é garantia de aprendizagem, porque o sentido não está apenas no objeto a ser manipulado, e, sim, nas suas representações.

Os conceitos matemáticos são construídos com bases em estruturas lógicas e não apresentam multiplicidade de sentidos. Como a lógica refuta a multiplicidade de sentidos, não é preciso buscar sempre no objeto este sentido único, pois muitas vezes ele está dado sem a necessidade de remeter-se ao exterior da própria lógica.

Wittgenstein (2000, p. 45) ressalta que "quando alguém tenta ensinar-nos matemática não começa por garantir-nos que sabe que $\mathrm{a}+\mathrm{b}=\mathrm{b}+\mathrm{a}$ ", usando a palavra "sabe" em itálico, o que denota que quem ensina deve mostrar "como" conhece aquilo que está ensinando. $\mathrm{O}$ ensinante, ao mostrar o "como" sabe a quem ensina, justifica seus ensinamentos, sem precisar recorrer a ousadas técnicas pedagógicas. Dessa forma, saber ensinar matemática não é simplesmente saber o que se ensina. É preciso saber mostrar como sabe o que ensina. Para isso, o professor deve refletir sobre o seu saber e adentrar num nível elevado de abstração.

É provável que o aluno resista à matemática porque resiste à abstração. Se este fato é verdadeiro, cabe perguntar os motivos pelos quais o aluno resiste à abstração. Todas as disciplinas trabalham com certo nível de abstração. A abstração não reside na superfície de um problema ou de um fato, é preciso um mergulho na reflexão; talvez este seja o motivo pelo qual o sujeito a recuse e recue perante ela.

Nos encontros (congressos, seminários, cursos) de professores de matemática, muitas técnicas são recomendadas para ilustrar de forma mais contundente os conceitos da disciplina. Percebe-se que alguns professores ficam muito satisfeitos com formas diferenciadas de demonstrações práticas e de construção de conceitos através de material concreto. Estas atividades pretendem esclarecer ao aluno o objeto de estudo e pressupõem que os professores também precisam desta clareza. 
Stella Baruk revela sem constrangimentos as muitas horas gastas lendo livros para preparar suas aulas e que, posteriormente, seriam dadas em minutos. Ora, se o professor tem a necessidade de muito tempo para preparar uma aula, como pode exigir que em minutos seus alunos aprendam o que ele próprio levou tanto tempo para aprender a ensinar? Se o professor não tem muita clareza sobre um determinado conceito, como quer que seu aluno aprenda rápida e prontamente o que para ele próprio levou tanto tempo para que se mostrasse claro em sua mente?

Quanto à figura do professor de matemática ${ }^{3}$, Bachelard (1996, p. 304) diz:

É preciso também inquietar a razão e desfazer os hábitos do conhecimento objetivo. Deve ser, aliás, a prática pedagógica constante. Não deixa de ter uma ponta de sadismo, que mostra com clareza a interferência do desejo do poder no educador científico.

Desse modo, o autor exemplifica tal sadismo como a "atitude do professor de matemática, que se mostra sério e terrível como uma esfinge, não é difícil de psicanalisar".

Na minha prática de sala de aula, pude perceber tal sadismo, tanto de colegas de disciplina como também de alunos meus que atuaram no ensino fundamental e médio, o que, de certa forma, corrobora com a descrição de Bachelard.

Uma aluna, certa vez, ao comentar sobre a impossibilidade de reprovar seus alunos devido a uma lei municipal, disse-me: "Meu prazer é saber que eles vão rodar no vestibular".

O sujeito é "falado" pelo seu inconsciente, segundo a Psicanálise. Esta professora, ao reconhecer tal sentimento, mostra como desloca o prazer de poder reprovar. Sacrificando este prazer, busca outro: a reprovação de seu aluno pelo vestibular.

Outra aluna, também professora em escola regida pela mesma lei, salientou: "Não sei para que a gente estuda!" Seguindo a sua linha de raciocínio, estuda-se inclusive para reprovar. Sim, é verdade, nós professores devemos reprovar os alunos que não têm condições de passar para a série seguinte. Iludir o aluno não é ético. Mas incomodar-se por não poder reprovar parece um problema de outra ordem.

Uma colega advertiu seus alunos de que a prova seria difícil. Por que tal advertência? Pareceme que existe certo gozo nesta advertência, caso contrário bastaria que recomendasse mais tempo de estudos ou algo similar.

É evidente que há professores de outras disciplinas também sádicos, mas as características de sadismo se sobressaltam no professor de matemática. Ou, pelo menos, tornam-se mais visíveis diante de um contexto que reafirma o mito da dificuldade e medo em matemática.

Ainda existem professores de matemática que obrigam seus alunos a colocarem seus materiais escolares no chão em dias de prova. Essa atitude demonstra total falta de respeito e de confiança, pois parte do pressuposto que todo aluno traz consigo a intenção de "colar". A "cola", muitas vezes, representa um formulário que alguns professores permitem ao aluno ter acesso.

A pesquisa "Formação acadêmica, situação laboral e profissional dos professores de matemática do terceiro ciclo da educação geral básica e da educação diversificada" (REDUC), feita com professores da Costa Rica, demonstrou que "se assinala a porcentagem de professores que mostra satisfação com seu status de professor de matemática e sua situação laboral; e se indicam alguns fatores que segundo estes professores incidem em seu labor e causam insatisfação" (tradução minha). Isso aponta para vontade de poder deste professor, já que ensinar uma disciplina que é considerada difícil lhe dá status e este, por vez, representa poder.

Está aí o professor de matemática, "sem cosméticos e sem alegorias" (Nietzsche, 1983, p. 281), manifestando suas vontades, crendo em si mesmo e tendo orgulho de si mesmo.

Em contrapartida, o aluno também manifesta esta vontade de poder. Para ilustrar esta vontade do aluno, trago uma observação de Sara Pain (1993, p. 21):

O maravilhoso no número é a matemática do número, é o jogo da matemática como invenção humana. É isso o que temos que transmitir, porque se a criança pensa que nós estamos lhe ensinando Matemática para que conte carrinhos ou balas, isto não tem prestígio.

Não ter prestígio é não ter poder. Problematizar o processo educacional, inclusive do aluno de classes populares, desconsiderando os desejos desses alunos, é uma ingenuidade. Tirar o véu que encobre o aluno indefeso que aceita tudo que o professor propõe em sala de aula e desvendar a sua outra face mascarada pela pobreza mostra que o aluno 
também tem seus conflitos e não é um ser passivo e abnegado.

O problema aqui colocado não é o de defender ou criticar o professor e o aluno, e, sim, tentar entender o que impulsiona e o que impede o sucesso pretendido no ensino e na aprendizagem da matemática.

$\mathrm{O}$ ato de educar e de aprender coloca alguns impasses que não podem ser negligenciados. Se o sujeito-professor e o sujeito-aluno não têm completo domínio sobre o processo de conhecimento, temos que levar em conta suas rupturas e obstáculos, de forma que não se abra mão do acesso à tradição cultural.

Somos duplos, contudo não nos separamos como gomos de bergamotas. Andamos juntos, porém um se manifesta agora, o outro depois. Às vezes, nossas aulas são maravilhosas, às vezes horríveis. Não é fácil não sermos contraditórios, não conseguimos dar conta de tudo. Não temos controle do processo interno do aluno, mas também não temos o controle de nós mesmos. O professor é humano, demasiadamente humano.

Stella Baruk (1996) faz pertinentes críticas ao ensino da matemática, as quais nos fazem refletir muito sobre esta problemática na escola, mas não aponta alternativas ou soluções para o insucesso do aluno na disciplina.

Muitas vezes o aluno é, de fato, uma vítima desse tipo de ensino. Porém, em contrapartida, percebe-se a boa vontade do professor de matemática em querer ensinar melhor e também a seriedade com que, não raras vezes, ingenuamente adere à prática de uma teoria educacional desconhecendo seus fundamentos.

A busca pelo sucesso na educação é inevitável, pois tradicionalmente a educação alicerçada em bases sólidas vislumbra o êxito na escola. Mas igualmente temos que lidar com o insucesso do aluno e das teorias nas quais os professores se filiam e se amparam.

Não podemos acreditar em todas as vanguardas educacionais, mas também não podemos refutá-las por completo. Como diz Wittgenstein (2000, p. 47): "Quem tentasse duvidar de tudo, não iria tão longe como se duvidasse de qualquer coisa. $\mathrm{O}$ próprio jogo da dúvida pressupõe a certeza".

$$
\text { Prender-se a práticas educacionais }
$$

antiquadas sem tentar inovar é prejudicial ao ato de ensinar e aprender. É necessária uma constante mudança na forma de pensar o ato de ensinar e aprender, pois tanto aluno como professor nunca são os mesmos, eles mudam com o tempo.

"Dar aula" é um processo complexo, não existem fórmulas prontas. "Dar explicações" sem que haja diálogo com os alunos, muitas vezes de costas para eles, não é suficiente. Deixar os alunos sem muitas explicações não é conveniente. Dialogar com os alunos pressupõe que seja inevitável o esquema 'perguntas e respostas'. É evidente que o professor fará o papel de dirigente neste esquema, mas caso o professor não obtenha respostas dos alunos, ele deverá conduzir os alunos a uma resposta ou responder por eles. Se o professor pergunta e não obtém respostas, é recomendável que ele refaça a pergunta com outras palavras, na tentativa de facilitar o entendimento do aluno. Se há críticas a este tipo de ensinamento, cabe perguntar se há outra forma de ensinar.

Rotular o professor como um sujeito que estaria sempre "mal intencionado" é pouco construtivo. Reconhecer suas falhas me parece salutar. Recriminar o professor que prevê perguntas e respostas e não apontar uma alternativa me parece uma atitude ingênua. É fácil e atraente responsabilizar o professor pelo fracasso escolar. Este discurso cabe para o professor autoritário e para o professor que trata o seu aluno como um sujeito que não pode aprender. Desconhecer a limitação do professor e o seu constante aprendizado na prática docente, parece-me também mostrar limitações.

Existe um abismo entre escrever sobre a prática da sala de aula e sobre a prática propriamente dita. A escrita aceita um escritor sem prática docente que comente tal prática. Porém, a prática de sala de aula requer a experiência do professor. $\mathrm{Na}$ prática docente, existem aluno e professor que obtêm êxito, como existem aluno e professor que fracassam. Para aprimorar a prática de sala de aula, o importante é aprender com os erros e os fracassos.

\section{REFERÊNCIAS}

BACHELARD, Gaston. A formação do espírito científico: contribuição para uma psicanálise do conhecimento. Rio de Janeiro: Contraponto, 1996.

BARUK, Stella. Insucessos e Matemáticas. Lisboa / 
Portugal: Relógio D' Água Editores, 1996.

BEAN, Dale. O que é modelagem matemática? Revista da Sociedade Brasileira de Educação Matemática, São Paulo, n. 9/10, p. 49, 2001.

GIARDINETTO, José Roberto Boettger. Matemática escolar e matemática da vida cotidiana. Rio de Janeiro: Editora Autores Associados, 1998.

KANT, Immanuel. Prolegómenos a toda a metafísica futura. Lisboa: Edições 70, 1987.

NIETZSCHE, Friedrich. Para além de bem e de mal. São Paulo: Abril Cultural, 1983. (Coleção Os Pensadores)

PAIN, Sara. A arte e a construção do conhecimento. Revista do GEEMPA, n. 1,p. 19-27, jul., 1993.

SILVEIRA, Marisa R. Abreu da. A interpretação da matemática na escola, no dizer dos alunos: ressonâncias do sentido de "dificuldade". Porto Alegre: UFRGS, 2000. Dissertação (Mestrado).

WITTGENSTEIN, Ludwig. Da certeza. Lisboa: Edições 70, 2000.

.Investigações Filosóficas. Rio de Janeiro : Coleção Pensamento Humano, 1996.

.Observaciones sobre los fundamentos de la matemática. Madrid: Alianza Editorial, 1987. 